\title{
Atherectomy Rotating Component Length
}

National Cancer Institute

\section{Source}

National Cancer Institute. Atherectomy Rotating Component Length. NCI Thesaurus.

Code C150243.

The length of the rotating component of an atherectomy device. 